\title{
Urban-rural gradient detection using multivariate spatial analysis and landscape metrics
}

\author{
Marco Vizzari, ${ }^{1}$ Maurizia Sigura² \\ ${ }^{1}$ Corresponding Author, Department of Man and Territory. University of Perugia, Perugia, Italy; \\ ${ }^{2}$ Department of Agricultural and Environmental Sciences, University of Udine, Udine, Italy
}

\begin{abstract}
The gradient approach allows for an innovative representation of landscape composition and configuration not presupposing spatial discontinuities typical of the conventional methods of analysis. Also the urban-rural dichotomy can be better understood through a continuous landscape gradient whose characterization changes accordingly to natural and anthropic variables taken into account and to the spatio-temporal scale adopted for the study. The research was aimed at the analysis of an urban-rural gradient within a study area located in central Italy, using spatial indicators associated with urbanization, agriculture and natural elements. A multivariate spatial analysis (MSA) of such indicators enabled the identification of urban, agricultural and natural dominated areas, as well as specific landscape transitions where the most relevant relationships between agriculture and other landscape components were detected. Landscapes derived from MSA were studied by a set of key landscape pattern metrics within a framework oriented to the structural characterization of the whole urban-rural gradient. The results showed two distinct sub-gradients: one urban-agricultural and one agricultural-natural, both characterized by different fringe areas. This application highlighted how the proposed methodology can represent a reliable approach supporting modern landscape planning and management.
\end{abstract}

\section{Introduction}

Correspondence: Marco Vizzari, Department of Man and Territory. University of Perugia, Borgo XX Giugno 74, 06131 Perugia, Italy.

Key words: agriculture, kernel density estimation, landscape metrics, multivariate spatial analysis, transitional landscapes, urban-rural gradient.

Acknowledgements: this study was developed within a wider project named "Agricultural peri-urban landscapes of Umbria: identification, planning, and management", funded in 2009 by the Bank of Perugia Foundation.

(C) Copyright M. Vizzari and M. Sigura et al., 2013

Licensee PAGEPress, Italy

Journal of Agricultural Engineering 2013; XLIV(s2):e91

doi:10.4081/jae.2013.s2.e91

This article is distributed under the terms of the Creative Commons Attribution Noncommercial License (by-nc 3.0) which permits any noncommercial use, distribution, and reproduction in any medium, provided the original author(s) and source are credited.
European landscapes are intensively changing because human impacts on ecosystems are increasing at unprecedented and accelerated rates (Pearson and McAlpine, 2010). Human activities are the major forces in shaping landscape, creating a mosaic of natural and human-managed patches that vary in type, size, shape, and arrangement. Landscape structure and ecosystem configuration are critical to understanding ecological processes and functions since they directly affect the distribution of energy, materials, and species. Human influences on landscape structure are so numerous and different as to necessitate an analysis of their combined effects through a gradient of landscape modifications (Godron and Forman, 1983). The gradient analysis is a well established approach to study the ecology and the distribution of plants and animals in response to physical, chemical, ecological and climatic conditions of the environment. Simple gradients, as well as complex gradients can be found in landscapes. The former refer to environmental series due to a single measured environmental factor, while the latter are generated by several factors (man-made or natural) some of which may interact (McDonnell et al., 1993). Anthropogenic gradients were defined by Forman and Godron (1986) as the succession in the space of natural-managed-cultivated-suburban-urban landscapes. Along this gradient, a progressive change in the landscape structure can be observed and different characteristics of structural elements can be pointed out. Moving from the most natural to the most humanized landscape, man-made patches tend to increase, while natural resources patches tend to decrease. Patch density, and in general fragmentation, tends to increase as well as the regularity of patch shape, whereas the mean values of patch size and landscape connectivity tend to decrease.

In the gradient view, the urban-rural dichotomy can be thought of as a landscape gradient, if considered as a sliding level of human influence from rural to urban landscape, including ecological processes, flows and movements of goods, energy, people, capital, and information (Modica et al., 2012). The urban-rural gradient approach is commonly used to investigate how urbanisation phenomena are changing the ecological patterns and related processes across the landscape (McDonnell and Pickett, 1990; Luck and Wu, 2002; Hahs and McDonnell, 2006; Yang et al., 2010). Urbanization itself can be considered as a particular environmental gradient that produces relevant modifications on the structures and functions of ecological systems (McDonnell and Hahs, 2008). Moreover the urban-rural gradient analysis turns out to be fundamental in the identification and characterization of specific land use/land cover transition areas, characterized by peculiar and crucial ecological processes such as the periurban and the agro-forestry fringes. In the light of such complexity, the analysis of spatio-temporal and morpho-functional dynamics of landscape gradients should be supported by efficient and objective quantitative approaches based on methods aimed at the modelling of spatial data. Gradient analysis and landscape pattern analysis seem appropriate for such studies (Luck and Wu, 2002; Zhang et al, 2004). One effective method for representing and analysing landscape gradients is using Kernel Density Estimation (KDE) techniques applied on inten- 
sity indicators associated with geographic features (Torrens and Alberti, 2000; Vizzari, 2011a; Vizzari, 2011b; Modica et al., 2012).

The quantification of spatial heterogeneity of landscape is necessary to explore relationships between ecological processes and spatial patterns (Forman \& Godron, 1986; Palmer, 2008; Turner, 1990). A great variety of metrics aimed at the study of landscape composition and configuration were developed and applied to the analysis of urbanized systems (Wu, 2000; Botequilha Leitão and Ahern 2002; Li et al., 2005; Uuemaa et al., 2009).

In order to capture the spatial structure generated by land uses, this study integrates gradient analysis with pattern metrics to quantitatively characterize the landscape. The central assumption is that urbanrural gradient structure is mainly determined by three key components which generate, in turn, detectable landscape gradients: urbanization, agriculture and natural elements. Detection and analysis of the spatial organization of these main gradients are key steps for understanding the complexity of anthropized landscapes. Within this framework we aimed to address three core goals: (1) representation and analysis of landscape gradients produced by urbanization, agriculture, and natural elements; (2) urban-rural gradient classification and subdivision through multivariate analysis of said gradients; (3) characterization of the gradient and landscapes obtained from the previous analysis, with a particular focus on peri-urban and agro-forestry fringes.

\section{Materials and methods}

The $493 \mathrm{Km}^{2}$ wide study area comprises the Italian municipalities of Assisi, Bastia, Bettona, and Cannara (Figure 1). The area is characterized by a very typical landscape of central Italy composed of $54 \%$ of agricultural land, $34 \%$ forests and semi-natural areas, $9 \%$ of built-up areas and $3 \%$ of wetlands and water bodies (Corine Land Cover 2006, personal elaboration). Morphologically the area is characterized by a central wide plain in which intensive agricultural farms, urban and productive settlements are located. At the edge of this plain (on the NE and SW) there are two low hillsides dominated by very typical olive-growing agricultural area. The innermost higher hills are occupied mainly by agroforestry areas, woodlands and grasslands of varying extent. In the middle of the area is Mount Subasio (1290 m), which, together with the city of Assisi, is the most prominent element of cultural identity for the entire landscape under investigation. The area, because of its characteristics and ongoing transformations, was considered very appropriate for the application and validation of the proposed methodology. The general purpose was the exploration of the spatio-functional relationships between the key landscape components in order to identify sensible and representative areas on which to define sound guidelines supporting spatial planning. The methodology was developed through three main steps: (a) spatial modelling of gradients generated by key landscape components; (b) multivariate spatial analysis and landscape classification; (c) analysis of landscape structure.

\section{Spatial modelling of gradients generated by key landscape components}

Urbanization, agriculture, and natural elements were assumed to be key components of the urban-rural gradient of the area and represented and analysed independently. In view of the specific nature of their landscape gradients, a continuous analytical approach for the representation of these variables was adopted. GIS gridding techniques were applied to interpolate a defined pool of values for variables, referring to known parts of the territory, in order to reconstruct the most likely distribution of the phenomenon in the entire study area (Bailey and

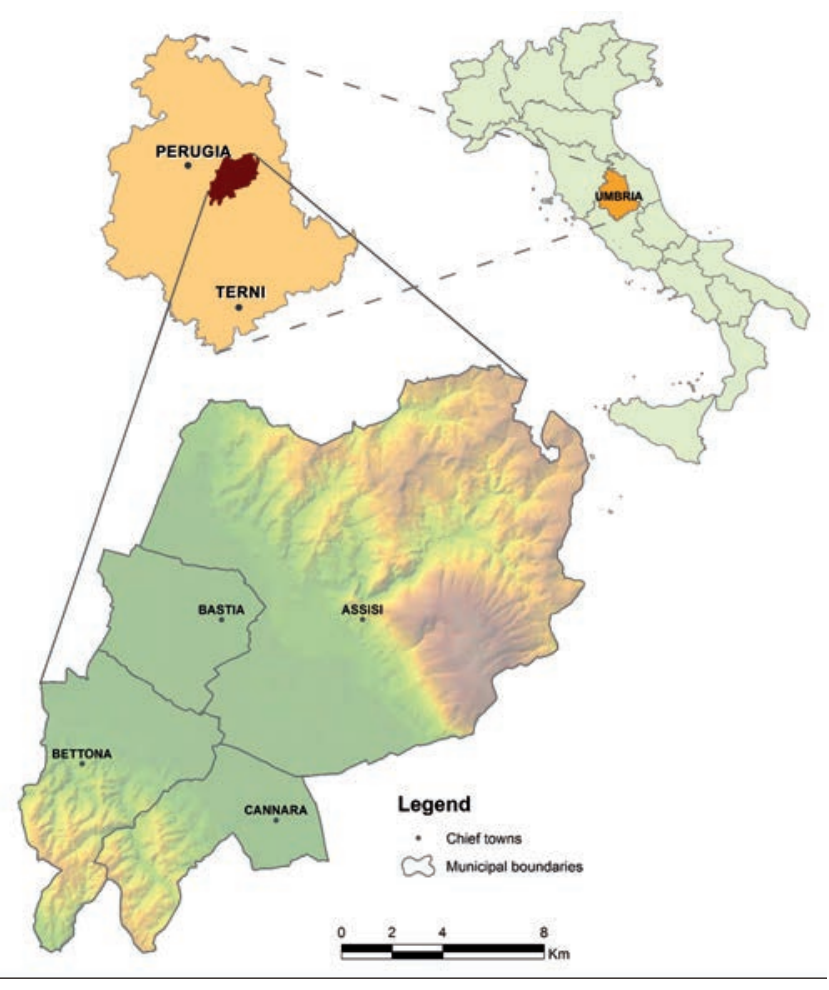

Figure 1. Geographic location of the area under investigation.

Gatrell, 1995; Longley et al., 2005; Smith et al., 2007). Between the various gridding techniques, density analysis makes it possible to transform values measured at specific locations as continuous surfaces representing the general trend of the spatial distribution for the considered variable. Kernel Density Estimation (KDE) is a particular density analysis that produces smoother surfaces, according to a kernel function, that appears more representative of landscape gradients (Vizzari, 2011b). In KDE, a moving window is superimposed over a grid of locations and the density of events is estimated at each location using a distance-weighted function, with the degree of smoothing controlled by the kernel bandwidth (Gatrell et al., 1996). The application of KDE requires the choice of the kernel function (e.g.: Gaussian, triangular, quartic) and the definition of three key parameters: bandwidth, cell size and intensity (Silverman, 1986). However the choice among the various kernel functions does not significantly affect the outcomes of the process (Epanechnikov, 1969). Differently, bandwidth definition represents the most problematic step, but also the most useful for exploratory purposes, since a wider radius shows a more general trend over the study area, smoothing the spatial variation of the phenomenon, while a narrower radius highlights more localized effects such as 'peaks and troughs' in the distribution (Jones et al., 1996; Borruso, 2008). Despite the many approaches available in the literature, visual examination of the resulting surfaces for different values of bandwidth remains a common method supporting the definition of this parameter (Bailey and Gatrell, 1995; Lloyd, 2007; Vizzari, 2011b). A bandwidth of $500 \mathrm{~m}$ was considered effective for a reliable generalization of landscape gradient at the scale adopted for the analysis. Cell dimension was set to $50 \mathrm{~m}$, a lower value than the coarsest legible resolution according to Hengl (2006). 


\section{Multivariate spatial analysis and landscape classification}

The spatial relationships between the gradient's components were subsequently analyzed using a multivariate technique based on the ISODATA (Iterative Self-Organizing Data Analysis Technique A) algorithm (Ball and Hall, 1965, Richards, 1999). This technique makes it possible to organize the basic data into a number of groups (or clusters) such that units belonging to the same group are more similar, in accordance to a given similarity measure, than those units belonging to different groups. The number of clusters and their characteristics are to be determined a priori, even if the number of final groups may differ from the initial one as a result of the optimization procedures for this method. Prior to the application of the ISODATA technique, it is appropriate to proceed with suitable variable standardization in order to avoid that the different ranges of variation may alter the final classification. In this application standardization has been performed through a linear normalization between 0 and 1 .

\section{Analysis of landscapes structure}

A set of landscape metrics was used for this study including patch density (PD), mean patch size (MPS), edge density (ED), largest patch index (LPI), landscape shape index (LSI), Simpson's evenness index (SIEI), and percentage of landscape (PLAND) (Table 1). Certain metrics were used to examine landscape-level properties, i.e. to describe the spatial patterns of all land-use types as a whole. Other metrics were used to examine class-level properties, i.e. to describe the spatial patterns of different land-use types in the urban-rural and agriculturalforestry fringe areas.

At the landscape level, dynamics of patch size, patch density, shape and landscape diversity were detected and some of the hypotheses on landscape structural responses along a human transformation gradient, as postulated by Forman and Godron (1986), were tested.

Considering the non-normal distribution of the data and the different composition of samples, the influence of urban-rural gradient on the landscape configuration was examined on each metric using a rank-based (Kruskal-Wallis) modified robust Brown-Forsythe Levene-

Table 1. Landscape metrics (based on McGarigal and Marks, 1995) used to quantify the spatial patterns of landscape types along the urban-rural gradient.

\begin{tabular}{|c|c|c|}
\hline Landscape metric & Abbreviation & Description \\
\hline Patch Density (n./100 ha) & PD & $\begin{array}{c}\text { Number of patche } \\
\text { per } 100 \text { ha }\end{array}$ \\
\hline Edge Density & ED & $\begin{array}{l}\text { Amount of edge relative } \\
\text { to the landscape area }\end{array}$ \\
\hline Mean patch size (ha) & MPS & $\begin{array}{c}\text { Average area of landscape } \\
\text { patches }\end{array}$ \\
\hline Largest patch index (\%) & LPI & $\begin{array}{l}\text { Ratio between the area of } \\
\text { the largest patch and the total } \\
\text { landscape area }\end{array}$ \\
\hline Landscape shape index & LSI & $\begin{array}{c}\text { Total length of patches edges } \\
\text { divided by the total area adjusted } \\
\text { by a constant for a square standard } \\
\text { (raster format) }\end{array}$ \\
\hline Simpson's Evenness Index & SIEI & $\begin{array}{l}\text { Measure of the distribution of area } \\
\text { among patch types }\end{array}$ \\
\hline Percentage of Landscape & PLAND & $\begin{array}{l}\text { Measure of percentage } \\
\text { of patch types }\end{array}$ \\
\hline
\end{tabular}

type test based on the absolute deviations from the median (Hines and Hines, 2000). Peri-urban and agro-forestry fringes were analysed on the basis of landscape composition using the PLAND metrics to better understand the roles of the different land uses in influencing the fringe areas (Table 1). In this phase eight classes of land use were considered: woodlands, orchards, olive groves, vineyards, built-up areas, grasslands, arable land with trees, arable land.

\section{Results}

\section{Urban-rural gradient detection and characterization}

\section{Landscape gradient generated by urbanization}

The landscape gradient determined by urbanization was studied analysing the population density by means of official census data available for the year 2000 (ISTAT, 2001). However, using census zones as a geographic reference of the population data may generate spatial inconsistencies especially in wider, less populated zones. Thus, the positional accuracy of census data was improved using the polygons of built-up classes contained in the 2000 Land Use and Land Cover (RERU, 2002) through a spatial matching process of the two datasets. This approach made it possible to associate every point of the total population of a census zone averaged with the total number of points falling in the same zone. On this last dataset a KDE analysis, using the parameters specified previously, was performed generating a spatial index known as UDI (Urban Density Index). The index, which expresses the number of inhabitants per square kilometre, allowed an effective representation of the urbanization gradient of the area under investigation.

\section{Landscape gradient generated by agriculture}

The landscape gradients generated by agricultural land uses were studied separating two different components that appear dominant within the landscape under investigation: arable crops and olive groves. Since these two kinds of cultivations produce very different agro-ecosystems, the relative spatial gradients have been represented and analyzed separately. The spatial distribution of arable crops was obtained through the Common Agricultural Policy (CAP) data for the year 2000 linked with the georeferenced centroids of the cadastral parcels. The use of the parcel centroids, instead of the polygons, helped to solve the problems related to multiple correspondence between CAP and cadastral data, related to the presence of multiple agricultural uses within the same parcel. Landscape gradient generated by olive groves was analyzed using national olive trees inventories available for year 2000. A double KDE procedure based on the parameters defined above produced an Arable crops Density Index (ADI) and an Olive groves Density Index (ODI). The former represents the percentage of total landscape area occupied by arable crops, while the latter expresses the number of olive trees per hectare of surface. The combined interpretation of the two indices supported the analysis of the spatial configuration and composition of the agricultural gradients within the study area.

\section{Landscape gradient generated by natural elements}

In order to proceed with the analysis of this gradient, forests and grassland polygons were extracted from the LULC 2000 dataset with the aim of isolating the elements with natural characteristics useful for representing the natural gradient. Again on this dataset we applied the KDE using the same parameters defined above. Analysis of the natural elements density has produced a continuous index, known as NDI (Natural elements Density Index), which expresses locally the ratio between the area occupied by the natural elements and the total land- 
scape area. This index made it possible to effectively represent the landscape gradient generated by the natural elements within the landscape under investigation.

\section{Landscape subdivision and classification}

Starting from ten classes set initially, the ISODATA multivariate analysis produced eight final clusters which were denominated according to their specific characteristics (Figure 2). The clusters, considering their particular composition, can be ordered according to a typical sequence of an urban-rural gradient of central Italy, plotting on a graph the outcomes of the four gradient indicators (Figure 3). For the purpose of an overall analysis of the agricultural intensity, the two indicators ADI and ODI can be summed into a single indicator for better understand the general trend of the agricultural density along the same gradient (Figure 3).

\section{Landscape pattern analysis}

The multivariate analysis allowed the classification of different landscape patterns along the urban-rural gradient. For five of the seven landscape metrics Levene's test highlighted different variances among the eight sample classes (Table 2). Only ED showed homogeneity of variances between the landscape clusters. Patch size coefficient of variation were most distinct in agricultural landscapes (AMI, AHI, AOG, AFN) and natural landscapes (ANT, NL) than in urbanized areas (U, UAT).

In order to study the evolution of the metrics along the gradient, the latter were plotted using box-plot graphs ordered according to the sequence defined previously (Figure 4). Patch Density increases from urbanized areas to agricultural landscape, with the exception of intensive agricultural landscape (AHI) where the value decreases dramatically. The same metric decreases progressively moving from traditional agricultural areas (AOG) to the most natural ones. In general, landscapes dominated by traditional agriculture (AOG, AFM) and natural land covers (ANT, NL), as well as, in the intensive agricultural landscapes (AHI) are characterized by lower variability in PD. Regarding dominance of the landscape by few land uses, LPI shows high variability for all the landscapes defined by the gradient. The highest median values were found for urbanized areas (U), intensive agricultural landscape (AHI) and natural landscapes (NL), as an effect of an extent matrix represented by settlements, croplands and forest habitat respectively.

Information regarding landscape fragmentation also came from the ED index (not represented since highly correlated to PD), as we assumed low values associated with a lower number of interfaces between different types of patches and consequently less variation in patch shape. ED highlights the relative simplification of intensive agricultural landscapes, while transitional ones, both from urban to agricultural (U to AMI) and from agricultural to natural (AOG to NL) are characterized, respectively, by an increasing and decreasing trend of diversity in their structure. These results were confirmed by LSI, showing a parabolic shape trend moving from most urbanized (U) to agricultural intensive landscapes (AHI). The higher shape complexity is associated with traditional agricultural landscapes (AOG), dominated by olive groves, while, moving towards the most natural landscapes (NL), LSI assumes low values on average, but with a high variability, within landscapes oriented to agro-forestry activities (AFM) and in the seminatural ones (ANT). Landscape simplification for intensive cultivated landscapes are also confirmed by the SIEI, while an even distribution among patch types results especially in transition landscapes from urban to agricultural areas (UAT and AMI) and in less intensive agricultural landscapes (AOG, AFM, and ANT).

The analysis of landscape composition (PLAND), developed specifically for peri-urban and agro-forestry transitional landscapes (UAT, AMI, AFM, ANT), shows a diffuse presence of settlements, but their

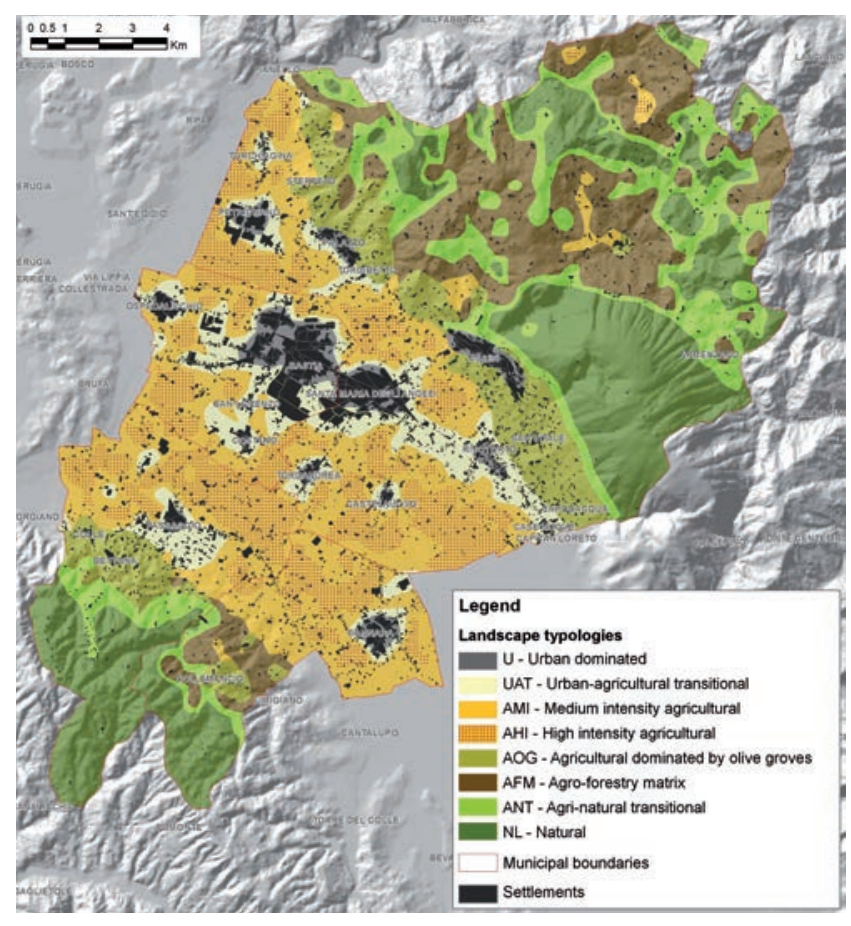

Figure 2. Landscape subdivision generated by cluster analysis.

Table 2. Sample size and mean value of metrics calculated for the landscape types. Modified robust Brown Forsythe Levene type tests were significant showing different variances between the datasets.

\begin{tabular}{lcccccccc} 
Landscapes & U & UAT & AMI & AHI & AOG & AFM & ANI \\
Sample size & 11 & 16 & 10 & 28 & 9 & 15 & 14 & 14 \\
MPS (ha) & $2,44^{*}$ & $1,72^{*}$ & $1,27^{*}$ & $3,28^{*}$ & $1,31^{*}$ & $2,01^{*}$ & $2,37^{*}$ & $8,03^{*}$ \\
\hline PD (n./100 ha) & $56^{*}$ & $73^{*}$ & $86^{*}$ & $36^{*}$ & $85^{*}$ & $58^{*}$ & $47^{*}$ & $25^{*}$ \\
ED (m/ha) & 232 & 297 & 327 & 168 & 305 & 264 & 252 & 169 \\
\hline LPI (\%) & $67^{*}$ & $40^{*}$ & $52^{*}$ & $82^{*}$ & $37^{*}$ & $39^{*}$ & $46^{*}$ & $62^{*}$ \\
LSI & $4,44^{*}$ & $6,43^{*}$ & $7,53^{*}$ & $3,36^{*}$ & $9,37^{*}$ & $7,29^{*}$ & $7,00^{*}$ & $4,19^{*}$ \\
\hline SIEI & $0,54^{*}$ & $0,63^{*}$ & $0,57^{*}$ & $0,22^{*}$ & $0,75^{*}$ & $0,71^{*}$ & $0,69^{*}$ & $0,51^{*}$ \\
\hline$*=$ P<0,05 & & & & & & & &
\end{tabular}



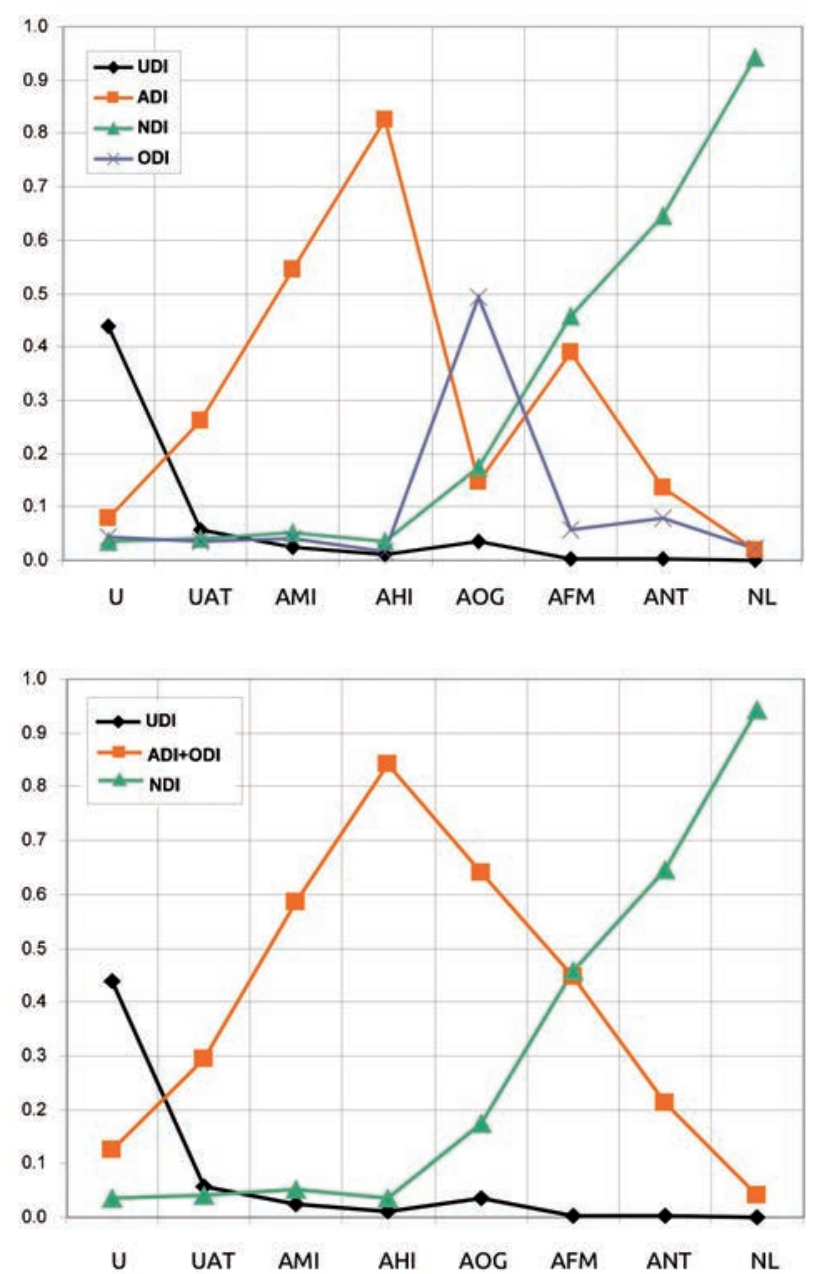

Figure 3. Average values of the four spatial indicators within the landscapes typologies located along the urban-rural gradient.
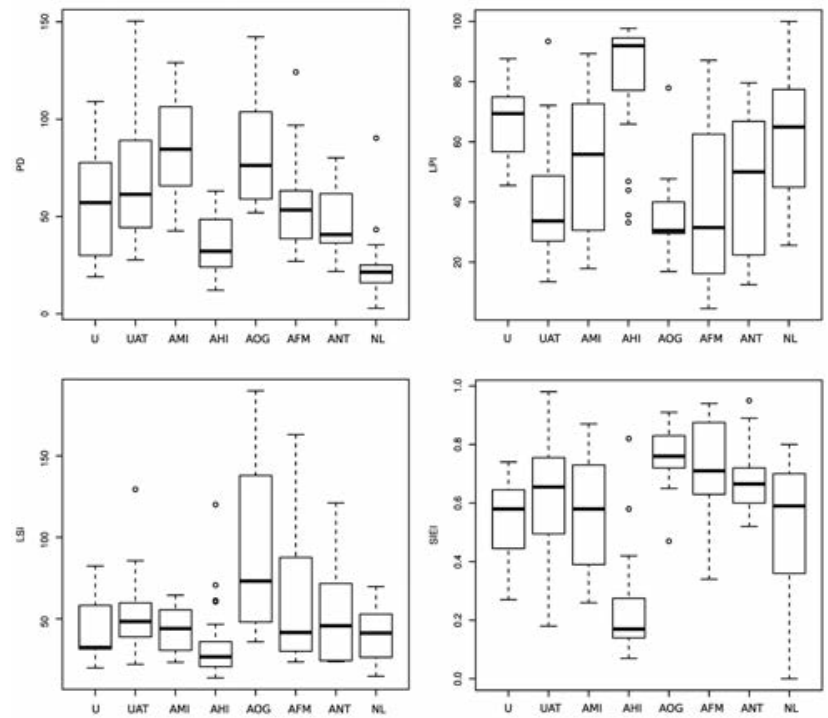

Figure 4. Values of Patch Density index (PD), Largest patch index (LPI), Landscape shape index (LSI), Simpson's Evenness Index (SIEI) for the landscape typologies located along the gradient. Median (line within the white box), upper and lower quartiles (box), maximum-minimum range (whiskers) and outliers are shown. incidence indicates an evident characterizing function only in transitional urban-agricultural landscapes (UAT) (Table 3). The occurrence of arable land within the four landscape typologies is generally higher, also influencing the most natural landscapes. Semi-natural habitats play an important role only in the rural-forestry fringes, while in the urban rural fringe, a lower percentage of area is occupied by woodlands. Otherwise, the tree crops (olive groves, orchards, and vineyards) are less important for the characterization of the four landscapes.

\section{Discussion}

The gradient modelling and the subsequent multivariate analysis conducted to an effective classification in eight landscape typologies, reflects the spatial variability of the area under investigation. Each landscape typology represents a specific portion of the urban-rural gradient and is differentiated by a peculiar composition and configuration.

An overall analysis of the results suggests the subdivision of the general urban-rural gradient of the area into two sub-gradients: an urbanagricultural one (UAsg, from landscapes $\mathrm{U}$ to $\mathrm{AHI}$ ) and an agriculturalnatural one (ANsg, from landscapes AHI to N). The former is characterized by a decreasing incidence of urbanization and an increasing level of agriculture, while the latter is distinguished by an increasing level of natural and semi-natural land covers and a decreasing incidence of agricultural uses. Between the extremes of each sub-gradient can be identified interesting transitional landscapes with very peculiar characteristics and transformations related to their diversity and to the relevant spatio-functional interactions between their variegated land uses and covers. The transitional landscape of the UAsg (UAT and AMI) shows a medium diversity and is characterized by a consistent interaction between urban and agricultural areas. The most relevant transformations within these landscapes are related to typical urban dynamics (soil sealing, build-up sprawl and spreading, roads development) to the detriment of agricultural diversity. Differently, the transitional landscapes of AHsg (AOG, AFM, and ANT) are characterized by the higher diversity of the area and enclose a very relevant agro-forestry mosaic. The AFM and ANT landscapes contain the most important high natural value farmland of the area under investigation. Within these contexts the low input and extensive agriculture supports, or is associated with, either a high species and habitat diversity or the presence of species of conservation concern (Andersen et al., 2003; Paracchini et al., 2008).

These results partially confirm the generally predictable characteristics for landscapes in similar human gradients postulated by Forman and Godron (1986). Moreover our results broadly agree with

Table 3. Percentage of landscape (PLAND) of different LULC classes within transitional landscapes.

\begin{tabular}{lcccc}
\hline LULC classes & UAT & AMI & AFM & ANT \\
Woodlands & 3 & 4 & 31 & 58 \\
Orchards & 0 & 0 & 0 & 0 \\
\hline Olive groves & 1 & 2 & 5 & 6 \\
Vineyards & 3 & 3 & 0 & 0 \\
\hline Built-up areas & 26 & 9 & 4 & 2 \\
Grasslands & 0 & 0 & 8 & 13 \\
\hline Arable lands with trees & 4 & 2 & 3 & 1 \\
Arable lands & 63 & 80 & 49 & 20
\end{tabular}


those obtained from analyses of urban to rural gradients in metropolitan areas. Zhang et al. (2004) from a GIS-based gradient analysis of urban landscape pattern of the Shanghai metropolitan area, point out an increasing patch density (PD), edge density (ED), and landscape shape complexity (LSI), and sharp decreases in the la rgest and mean patch size (LPI and MPS). However, in the USA urban land use is associated with the least values for mean patch size and largest patch index and with the largest patch density (Luck and Wu, 2002). A positive relationship between fragmentation and the degree of urbanization has been demonstrated by increases in patch density and decreases in mean patch size from the urban centre to the surrounding fringe areas, while rural landscapes are single land-use dominant and homogeneous (Weng, 2007). In our study this evidence is generally verified except for the traditional rural landscapes which are characterized by a great heterogeneity due to the traditional mosaic of croplands. From the rural-forestry fringes to the natural landscapes, fragmentation of patterns decreased again, but in favour of woodland dominated and well connected natural habitats. Regarding landscape diversity the SIEI shows a quite fluctuating trend. It increased from urbanized areas to urban-agricultural transitional landscapes and then decreased dramatically in intensive agricultural landscape as a consequence of landscape simplification mainly due to agriculture intensification (Kleijn et al., 2011; Bonfanti et al., 1997).

\section{Conclusions}

The study adopted a combined method of gradient analysis and landscape metrics to analyze the landscape gradients due to urbanization, agriculture and natural land covers in a typical landscape of central Italy. The urban-rural gradient is one of the techniques commonly used to investigate how urbanisation is changing the ecological patterns and processes across the landscape. The strong interactions between the typical heterogeneous land use of the intermixed fringe areas make it necessary to consider agriculture as a key component of the system. The gradient approach and the multivariate analysis allowed the identification of eight landscape typologies, reflecting the spatial interaction of the landscape gradients considered in the analysis. Calculation of landscape metrics allowed a deeper comprehension of the landscape organization occurring along the urban to rural gradient. As a result, two different sub-gradients were identified: an urban-agricultural one (from urban to agricultural areas) and an agricultural-natural one (from agricultural to natural areas). The overall results pointed out distinct spatial signatures for urban rural fringes and rural-forestry fringes respectively from those of urban and cultivated landscapes. This evidence was found both for land use composition (Table 3) and for landscape configuration, demonstrated by different values of diversity, patch density and patch shape complexity (Figure 4 ). The specific characteristics of landscape structures reflect different and peculiar processes within the fringes areas. Land-use conflicts, species and habitat conservation, preservation of cultural heritage, changes of lifestyles, products and services from multifunctional agriculture are some of the main issues within peri-urban landscapes. Loss of productive agricultural land, increase in landslide risk, loss of biodiversity associated with agricultural management, degradation of cultural heritage represented by traditional man-made structures are key phenomena associated with agro-forestry landscapes. Identifying the landscape's gradients and patterns and the related ecological and socioeconomic issues is an important preliminary step for an effective spatial planning process.

\section{References}

Andersen E., Baldock D., Bennett H., Beaufoy G., Bignal E., Brouwer F., Elbersen B., Eiden G., Godeschalk F., Jones G., McCracken D.I., Nieuwenhuizen W., Van Eupen M., Hennekens S., Zervas G., 2003. Developing a high nature value indicator. Report for the European Environment Agency. Copenaghen.

Bailey T.C., Gatrell A.C., 1995. Interactive spatial data analysis, New York Wiley Geographical Analysis in Baller R.L., Anselin S., Messner G., Hawkins D. (Editors) Longman Higher Education, Harlow.

Ball G.H., Hall D.J. 1965. ISODATA, A novel method of data analysis and pattern classification. Stanford Research Institute, Menlo Park, California.

Bonfanti P., Fregonese A., Sigura M. 1997. Landscape analysis in areas affected by land consolidation. Landscape and Urban Planning, 37(1-2): 91-98.

Borruso G., 2008. Network Density Estimation: A GIS Approach for Analysing Point Patterns in a Network Space. Transactions in GIS 12: $377-402$.

Botequilha Leitão A., Ahern J. 2002. Applying landscape ecological concepts and metrics in sustainable landscape planning. Landscape Urban Planning 59 (2): 65-93.

Epanechnikov V.A. 1969. Nonparametric estimation of a multidimensional probability density. Teor. Veroyatnost. i Primenen. 14: 156161.

Forman R.T.T., Godron. M. 1986. Landscape ecology. John Wiley \& Sons, New York.

Gatrell A.C., Bailey T.C., Diggle P.J., Rowlingson B.S. 1996. Spatial point pattern analysis and its application in geographical epidemiology. Transactions of the Institute of British Geographers 21:256-274.

Godron M., Forman. R.T.T. 1983. Landscape modification and changing ecological characteristics. Pages 1-28 in Mooney H. A. and Godron M. (Eds). Disturbance and ecosystems. Springer-Verlag, New York, USA.

Hahs A.K., McDonnell M.J. 2006. Selecting independent measures to quantify Melbourne's urban-rural gradient. Land Urban Plan 78: 435-448.

Hengl T. 2006. Finding the right pixel size. Computers \& Geosciences 32: 1283-1298.

Hines W.G.S., Hines R.J.0. 2000. Increased power with modified forms of the Levene (med) test for heterogeneity of variance. Biometrics 56: 451-454.

ISTAT 2001, Italian National Institute of Statistics, "Basi territoriali e variabili censuarie", available from: http://www.istat.it/it/archivio/ 44523 (accessed on 06/14/2013).

Jones M.C., Marron J.S., Sheather S.J. 1996. A Brief Survey of Bandwidth Selection for Density Estimation. Journal of the American Statistical Association 91: 401-407.

Kleijn D., Rundlöf M., Scheper J., Smith H.G., Tscharntke T. 2011. Does conservation on farmland contribute to halting the biodiversity decline? Trends in Ecology \& Evolution 26: 474-481.

Li X., He H.S., Bu R., Wen Q., Chang Y., Hu Y., Li Y. 2005. The adequacy of different landscape metrics for various landscape patterns. Pattern Recognition 38: 2626-2638.

Lloyd: C.D., 2007. Local models for spatial analysis, Population English Edition. CRC Press.

Longley P.A., Goodchild M.F., Maguire D.J., Rhind D.W. 2005. Geographic Information Systems and Science, Information Systems Journal. Wiley.

Luck M., Wu J. 2002. A gradient analysis of urban landscape pattern: a case study from the Phoenix metropolitan region, Arizona, USA. Landscape Ecology 17:327-339. 
McDonnell M.J., Pickett S.T.A. 1990. Ecosystem structure and function along urban-rural gradients: an un exploited opportunity for ecology. Ecology 71:1232-1237.

McDonnell M.J., Pickett S.T.A., Pouyat R.V. 1993. The application of the ecological gradient paradigm to the study of urban effects. In: McDonnell, M.J., Pickett, S.T.A. (Eds.), Humans as Components of Ecosystems. Springer-Verlag, New York, NY, 175-189.

McDonnell, M.J., Hahs, A.K. 2008. The use of gradient analysis studies in advancing our understanding of the ecology of urbanizing landscapes: current status and future directions. Landscape Ecology, 23(10): 1143-1155.

McGarigal K., Marks B.J. 1995. FRAGSTATS: Spatial Pattern Analysis Program for Quantifying Landscape Structure, FRAGSTATS Manual. USDA Forest Service.

Modica G., Vizzari M., Pollino M., Fichera C.R., Zoccali P., Di Fazio S., 2012. Spatio-temporal analysis of the urban-rural gradient structure: an application in a Mediterranean mountainous landscape (Serra San Bruno, Italy). Earth System Dynamics 3: 263-279.

Palmer G.C., 2008. Principles and Methods in Landscape Ecology: Towards a Science of Landscape. Austral Ecology 33: 361-362.

Paracchini M.L., Petersen J.E., Hoogeveen Y., Bamps C., Burfield I., Van Swaay C. 2008. High Nature Value Farmland in Europe. An Estimate of the Distribution Patterns on the Basis of Land Cover and Biodiversity Data. Luxembourg.

Pearson D.M., McAlpine C. A. 2010. Landscape ecology: an integrated science for sustainability in a changing world. Landscape Ecology 25:1151-1154.

Richards J.A. 1999. Remote Sensing Digital Image Analysis: An Introduction. Springer-Verlag, Berlin.

Romano B., Ragni B., Orsomando E., Vizzari M., Pungetti G., 2009. Rete Ecologica regionale della Regione Umbria, Petruzzi editore, Perugia.
Silverman B.W., 1986. Density Estimation for Statistics and Data Analysis (Monographs on Statistics and Applied Probability). Chapman and Hall/CRC.

Smith M., Goodchild M., Longley P. 2007. Geospatial Analysis: A Comprehensive Guide to Principles, Techniques and Software Tools (2nd Edn). Matador.

Torrens P.A., Alberti M. 2000. Measuring sprawl. Smart Growth America Washington, DC, London.

Turner M.G., 1990. Spatial and temporal analysis of landscape patterns. Landscape Ecology 4: 21-30.

Uuemaa E., Antrop M., Roosaare J., Marja R., Mander U. 2009 Landscape Metrics and Indices: An Overview of Their Use in Landscape Research. Living Reviews in Landscape Research.

Vizzari M. 2011a. Spatial modelling of potential landscape quality. Applied Geography 31: 108-118.

Vizzari M. 2011b. Spatio-temporal analysis using urban-rural gradient modelling and landscape metrics. Lecture Notes in Computer Science 6782: 103-118.

Weng Y.C. 2007. Spatiotemporal changes of landscape pattern in response to urbanization. Landscape and Urban Planning 81: 341353.

Wu J. 2000. Landscape Ecology: Pattern, Process, Scale and Hierarchy. Higher Education Press, Beijing, China

Yang Y., Zhou Q., Gong J., Wang Y. 2010. Gradient analysis of landscape pattern spatial-temporal changes in Beijing metropolitan area, China. Science in China. Series E, Technological sciences 53: 9198.

Zhang L., Wu J., Zhen Y., Shu J. A. 2004. GIS-based gradient analysis of urban landscape pattern of Shanghai metropolitan area, China. Landscape and Urban Planning 69: 1-16. 